\title{
What in Fact Is the Role of Stylized Facts in Fundamental Research of Business and Information Systems Engineering?
}

DOI 10.1007/s12599-011-0149-5

\section{The Authors}

Prof. Dr. Peter Loos ( $\varangle)$

Institute for Information Systems

at DFKI

Saarland University

66123 Saarbrücken

Germany

loos@iwi.uni-sb.de

\section{Peter Fettke \\ Barbara E. Weißenberger \\ Stephan Zelewski \\ Armin Heinzl \\ Ulrich Frank \\ Juhani livari}

Published online: 2011-03-11

This article is also available in German in print and via http://www. wirtschaftsinformatik.de: Loos $P$, Fettke P, Weißenberger BE, Zelewski S, Heinzl A, Frank U, livari J (2011) Welche Rolle spielen eigentlich stilisierte Fakten in der Grundlagenforschung der Wirtschaftsinformatik? WIRTSCHAFTSINFORMATIK. doi: 10. 1007/s11576-011-0264-4.

(C) Gabler Verlag 2011

\section{Introduction}

In the discussion initiated by Winter on "What in fact is fundamental research in business and information systems engineering?" in issue $2 / 2009$, Zelewski submitted the interesting proposal to use the concept of stylized facts as developed in economics in business and information systems engineering (BISE) in order to promote theory building within our discipline (Winter et al. 2009). Stylized facts constitute elements of knowledge in the form of generalized statements that describe the important characteristics and relationships in the context of a studied phenomenon and are widely supported empirically. For example, the empirically proven relationship between the longterm abstention from changing the employer in Japanese companies and a much larger salary increase compared to U.S. companies is a typical stylized fact in economics.

When using stylized facts in the context of BISE, a number of interesting questions arise:

- What are the typical stylized facts within BISE?

- How can stylized facts be obtained systematically?

- What is the importance of stylized facts in design-oriented disciplines?

- Which role do stylized facts play in practice?

- What is the difference between technological rules and stylized facts? To what extent can we consider stylized facts to be "technological" knowledge about cause-effect-relationships that can be utilized for the construction of artifacts of information and communication technology?

- Which role do stylized facts play in empirical research?

- Which contribution can stylized facts make for building theories in BISE if a multiperspective research approach is assumed?

Currently, only scattered experience exists in the application of stylized facts in BISE (Fettke et al. 2010; Houy et al. $2009,2011)$. In order to achieve a broad perspective on the issue in the course of this discussion, well-known representatives from the field of business administration, the German-speaking BISE as well as from Information Systems Research were invited to comment on the topic. The following authors accepted our invitation to this discussion (in alphabetical order):

- Prof. Dr. Ulrich Frank, Chair of Information Systems and Enterprise Modelling, University of Duisburg-Essen, Germany;

- Prof. Dr. Armin Heinzl, Chair of General Management and Information Systems, Mannheim University, Germany;
- Prof. Dr. Juhani Iivari, Department of Information Processing Science, Oulu University, Finland;

- Prof. Dr. Barbara E. Weißenberger, Chair of Controlling and Business Accounting, Justus-Liebig University of Gießen, Germany;

- Prof. Dr. Stephan Zelewski, Institute of Production and Industrial Information Management, University of Duisburg-Essen, Germany.

Within their contributions the authors highlight different facets of the generation and application of stylized facts that appear relevant and important for BISE.

Barbara E. Weißenberger outlines the concept and the derivation of stylized facts based on a case study in the field of IT-based controlling systems. Thus, several empirical studies have shown that the "increasing flexibility of IT systems in accounting and control has a positive impact on management accounting and control". The author argues that the concept contributes to aggregate and structure fragmented knowledge in a research area, with particular emphasis on revealing research gaps. At the same time she points out that the derivation of stylized facts is the result of comprehensive research endeavors.

The contribution by Stephan Zelewski considers the concept of stylized facts in the tension between the more designoriented German-speaking BISE on the one hand and the more behavioristic Anglo-Saxon Information Systems Research on the other. He argues that stylized facts are not directly but indirectly fruitful for the design-oriented BISE: Accordingly, stylized facts form a "seed of crystallization" for the development and testing of theories with causal explanatory power, making it possible to "explain and verify prognoses regarding alleged effects of the recommended design measures". Despite the attractiveness of the concept, the author also points to difficulties in the implementation in current science.

Armin Heinzl identifies application areas for stylized facts in BISE, especially 
for revealing cause-effect-relationships and for theory testing. Stylized facts can be considered as boundary objects between the design-oriented research paradigm and empirical research paradigm. However, he points out two problems which complicate a utilization of stylized facts in our discipline. First, there is no large variety of data items available in BISE - in contrast to economics, for example. Also secondary data are scarcely available. Second, the author discusses methodological challenges for the application of stylized facts, and he emphasizes the danger of stylized facts being applied as an illigitimate, oversimplified alternative to rigorous empirical research in which case it would hinder the integration of exisiting theoretical knowledge into design-oriented research.

Ulrich Frank argues that stylized facts within BISE "can represent interesting patterns - but they do not have to". One risk is particularly seen in the fact that it is currently not clear what features distinguish scientifically important stylized facts, so that ultimately any statements may be labeled to be legitimated stylized facts. Furthermore, he points out that for the design-oriented BISE not only models of actual behavior are important, but rather the design of possible worlds is necessary.

The contribution by Juhani Iivari considers the potentials of stylized facts in particular from the perspective of Information Systems Research. The author highlights the aspect of idealizing stylized facts and draws parallels to the formation of so-called ideal types according to Weber in the social sciences. Moreover, he puts the presumption to discussion that the relationships between simplicity, utility, and acceptance of a technique as described in the Technology Acceptance Model (TAM) can be seen as stylized facts.

This discussion intends to stimulate the scientific discourse on the potentials, application, and limitations of stylized facts in fundamental BISE research. The scientific community is invited to participate in this discussion. If you would like to comment on this topic or another article of the journal Business \& Information Systems Engineering (BISE), please send your contribution (max. 2 DIN A4 pages) to the editor-in-chief, Prof. Hans Ul- rich Buhl, University of Augsburg, HansUlrich.Buhl@wiwi.uni-augsburg.de.

\section{Prof. Dr. Peter Loos, PD Dr. Peter Fettke IWi at DFKI} Saarland University, Germany

\section{Stylized Facts: A Suitable Approach for Fundamental Research?}

\subsection{Introduction}

In issue $2 / 2009$ of this journal, leading representatives discussed the question of the importance of fundamental research within the business and information systems engineering (BISE) discipline and the methodological concepts that might form its basis (Winter et al. 2009, p. 227 ff.). In this context, Zelewski introduced the method of "stylized facts" (SF) as a starting point to identify particularly promising issues for research in the field of BISE. The SF method can be traced backed to Kaldor (1961) and increasingly attracted attention in economic research in recent years again. Essentially, the identification of SF is based on the systematical identification of the state of the art of summarized expertise (Schwerin 2001, p. 103) in empirical research for an object of interest and supposed to be used as a starting point for further research, e.g., in hypothesis formulation or as an assumption within analytical models. This contribution presents an example of how SF can be obtained systematically and how relevant they may be for both (fundamental) scientific research and the transfer of research knowledge into business practice.

\subsection{Conceptual Foundations of the Stylized Facts Methodology}

The SF methodology is a form of literature synthesis which stands between the collection and analysis of literature on a problem (review) and the quantitative integration of empirical primary studies using statistical methods (meta-analysis). In contrast to the review methodology, SF only consider empirical findings on a matter of interest, and do so within the limits of a clearly structured and intersubjectively verifiable procedure. This also applies to the meta-analysis in a similar way, which, however, only allows for the evaluation of homogeneous (as regards content) and large quantitative surveys and aims at the validation of the respectively observed effect sizes.

Thus, all types of methodologically heterogeneous empirical primary studies can be used to derive SF. This meets the requirement for methodological triangulation, which today goes far beyond questions of objectification or validation of empirical statements, but is rather understood as a research strategy that helps to achieve a comprehensive understanding of the phenomena of interest (Denzin and Lincoln 2000, p. 5).

For the formulation of SF, first the key messages referring to the subject of interest are identified and taken literally from the included studies. These key messages are then grouped based on the dimensions that are relevant with regard to the problem definition and are summarized in view of their main implications. Here, the focus is mainly on the fundamental relationships. Aspects that refer only to details or a special context are not considered ("stylization," Heine et al. 2007 , p. 585). In a second step, the implications are further consolidated, resulting in overarching patterns, the so-called "stylized' facts" as defined by Kaldor (1961, p. 178).

In the literature, various requirements are imposed to SF (Weißenberger and Löhr 2007, p. 341). For instance, SF must be relevant for the particular problem (explanatory relevance), it should be possible to derive SF independent of the underlying methods or theories (methods or theory neutrality), and SF should be observable several times (indisputability of facts). Hence, the derivation of SF is liable to highly subjective leeway despite the clear structure of the underlying process methodology. Thus, the development of SF within a particular field of research is not only done by one researcher or research group alone, but by different experts reaching consensus on particular SF through academic discourse.

\subsection{Derivation of Stylized Facts: An Example}

The process of achieving SF will be explained below with an example originating from research from the related disciplines of controlling and business and information systems engineering (BISE). It is part of a wider investigation in the area of a controller's fields of action and role 
Table 1 Exemplary derivation of SF (Löhr 2010, pp. 272 f; original key messages in German language)

\begin{tabular}{|c|c|c|c|c|c|}
\hline Study & Page & Key messages & Implication & Stylized Fact & Quality \\
\hline 11 & 279 & $\begin{array}{l}\text { Managers expect from } \\
\text { management information } \\
\text { systems that they can be adjusted } \\
\text { to company-specific needs by } \\
\text { their own employees. }\end{array}$ & $\begin{array}{l}\text { Increasing individual } \\
\text { adaptability of management } \\
\text { information systems increases } \\
\text { the quality of management } \\
\text { accounting and control. }\end{array}$ & $\begin{array}{l}S F_{I T_{7} \text { : Increasing flexibility of IT }} \\
\text { systems in accounting and } \\
\text { control has a positive impact on } \\
\text { management accounting and } \\
\text { control. }\end{array}$ & B \\
\hline 16 & 665 & $\begin{array}{l}\text { The ability to react to changed } \\
\text { conditions by providing suitable } \\
\text { information is important for } \\
\text { controlling efficiency. }\end{array}$ & $\begin{array}{l}\text { Increased flexibility of IT systems } \\
\text { increases the suitability of } \\
\text { accounting information and the } \\
\text { efficiency of management } \\
\text { accounting and control. }\end{array}$ & & \\
\hline 114 & 163 & $\begin{array}{l}\text { The system-related quality } \\
\text { dimension of flexibility positively } \\
\text { affects the use of management } \\
\text { accounting information and } \\
\text { systems for strategic } \\
\text { decision-making. }\end{array}$ & $\begin{array}{l}\text { Increased flexibility of IT systems } \\
\text { increases the use of management } \\
\text { accounting information and } \\
\text { systems for strategic } \\
\text { decision-making. }\end{array}$ & & \\
\hline 139 & 67 & $\begin{array}{l}\text { The criterion of flexible } \\
\text { customization of ERP systems } \\
\text { has a strong effect on the } \\
\text { indicators of process } \\
\text { standardization, automation, and } \\
\text { specialization for large } \\
\text { enterprises. }\end{array}$ & $\begin{array}{l}\text { Increased flexibility of ERP } \\
\text { systems improves the } \\
\text { management accounting and } \\
\text { control processes. }\end{array}$ & & \\
\hline
\end{tabular}

perception on the one hand and the success of controlling and of the enterprise or project on the other hand (Löhr 2010, p. $266 \mathrm{ff}$.). Specifically, it deals with the relation between application and design features of controlling-relevant IT systems and the controlling or company or project success. During the years 1990 to 2009, 20 primary studies have been published in the German-language controlling literature on this subject. From these primary studies, Löhr extracts a total of 34 statements which are consolidated to a total of nine SF.

As an example, Table 1 shows the derivation of the SF "Increasing flexibility of IT systems in accounting and control has a positive impact on management accounting and control".

For the SF discussed here, findings from four studies on the relevant correlation can be extracted (Rosenhagen 1994; Becker and Benz 1997; Heidmann 2008; Forster et al. 2009). For this purpose, key messages were identified from each of the four studies that address the importance of flexibility of the IT systems used. In a second step, these statements are consolidated to implications in an abstract way and, in particular, detached from specific singular characteristics of the studies which are aggregated into the mentioned SF in a further step. Here, it is necessary to ensure that the statements and implications are characterized by a sufficient degree of consistency and representativeness (Weißenberger and Löhr 2007, p. 341). Löhr (2010, p. 195) categorizes the presented example of a SF to be averagely supported (B-SF), in contrast to a strongly supported SF (A-SF) which is based on implications from at least five studies. Overall, Fig. 1 shows the effect chains of the seven SF to controllingrelevant IT systems as derived by Löhr, which can be categorized as being averagely supported to strongly supported (including another SF mapping the influence of controlling success on company or project success as presented in another part of his study).

Based on these results, a variety of other research steps may follow.

1. First, one could try to question those SF that are only supported on average by means of further empirical studies, i.e. to identify SF that should be subject to further research (Winter et al. 2009 , p. 229). At the same time, issues that so far could not be empirically addressed to a sufficient extent, such as the influence of design features of ERP systems on management information systems for controlling purposes, could be investigated in order to identify further SF in the long term.

2. Second, the SF derived from the above mentioned field of research field could be transferred to an adjacent area of research in terms of a multi-level research approach (Hitt et al. 2007) in order to substantiate first hypotheses for specific effects in an exploratory approach (see also Löhr 2010 who applies the derived SF to issues of risk controlling).

3. Finally, the assumptions for the formulation of objective or formal analytical models as formulated in Fig. 1 may be used in the field of BISE. The statements are methodological assumptions which are merely capable of truth, but do not necessarily have to be true. For the acceptability of the modeling and for the transfer of results to business practice, however, it is indeed important to which extent individual assumptions are empirically supported.

\subsection{On the Importance of Stylized Facts for (Fundamental) Research and Knowledge Transfer}

The example presented in the previous section initially illustrates the performance of the SF methodology, but also its fundamental limits. These are characterized as such by the high subjectivity in the selection of the primary studies as well as in the consolidation of the SF, which is at least partly absorbed by the clearly structured and openly documented process 
Fig. 1 SF with regard to the impact of IT systems in management accounting and control on the success of controlling and the company or project (Löhr 2010, p. 274)

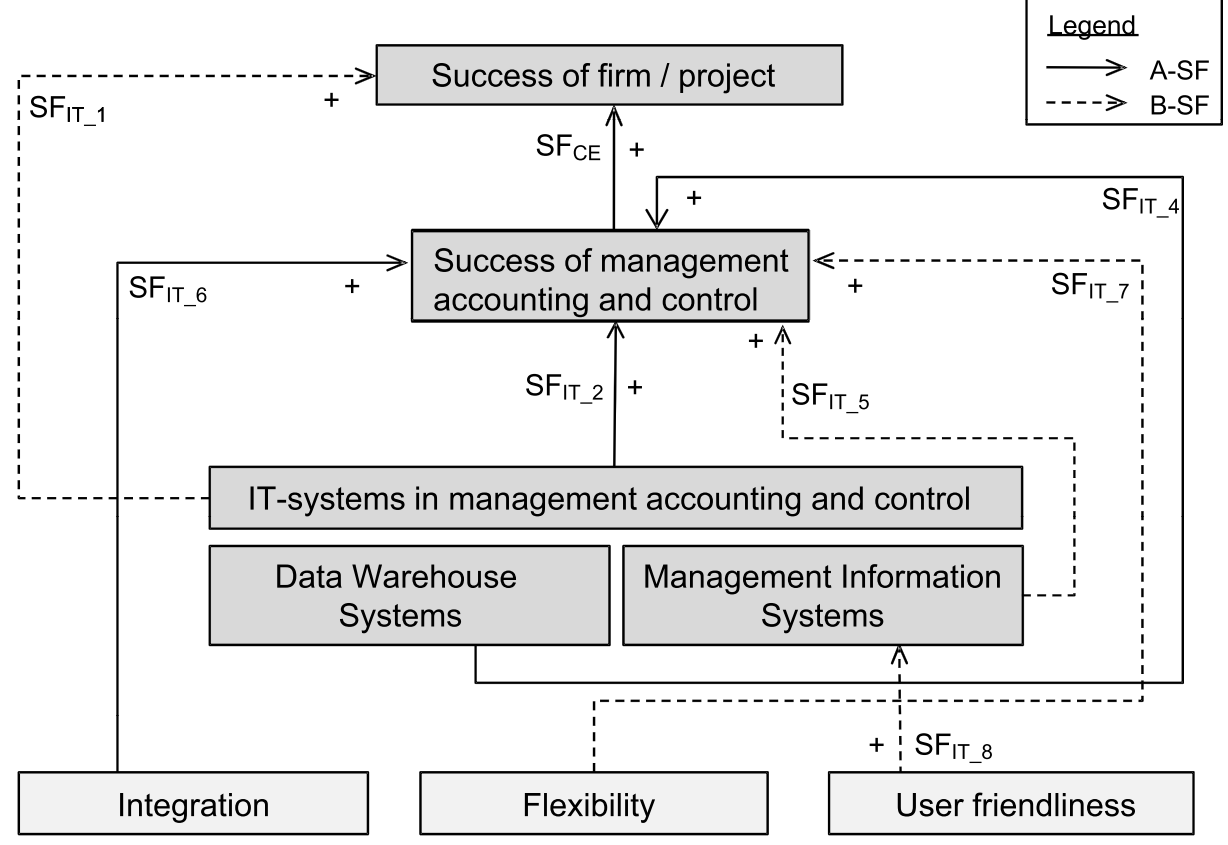

steps. However, it must still be critically observed that findings from related research areas which may be relevant to the formulation (or discarding) of SF are not considered if the search pattern for the primary studies is formulated too narrowly. A relatively broad search pattern that takes different research areas into account, however, may lead to a degree of complexity of the SF generation that can no longer be handled or quickly becomes very resource-intensive: The example illustrated in the previous section shows that the derivation of SF ultimately is the result of comprehensive research endeavors.

Another caveat relates to the distortions arising from the use of empirical studies per se. Thus, e.g., implications from unpublished studies inevitably cannot be taken into account. This may lead to the fact that SF about a phenomenon are derived in a scientific mainstream that appear stronger than they actually are in empirical reality. Finally, the problem is that in terms of scientific methods hypotheses as generalizations are never verified, but only not falsified. For empirical research, this means that the lack of rejection of a causal relationship does not necessarily indicate that the causal relationship actually exists (Ioannidis 2005). However, this is exactly what is assumed within the SF methodology.

Moreover, it is necessary to differentiate when answering the question of whether the SF methodology can be an appropriate concept for the (fundamental) research in a defined area of research as regards its performance for theory development. First, the application of the SF method assumes the presence of a sufficient number of primary studies within a field of research. A new development of theories or even the impetus for a paradigm shift is possible if implications of the used primary studies that are summarized to SF implications can be classified only with difficulty into the existing theoretical framework on the phenomenon of interest. The extent to which this is a promising research strategy in practice, however, is problematic as already the selection of included primary studies needs to be based on a theoretical framework. It appears unlikely that the SF identified then go beyond the scope of that framework.

Therefore, the main application of the SF method is probably less the formation of theories, such as Houy et al. (2009, p. 32) suggest, but rather the further development of existing theories by mapping the existing knowledge and knowledge gaps. As a result of the methodological heterogeneity of the primary studies used and the gradual abstraction or summarization of the relevant evidence, the SF method has the advantage to counteract the often lamented fragmentation of knowledge (Schreyögg 2007, p. 3) and to stabilize the considered theory by means of its empirical explication.

In this context, the combination of SF methodology and multi-level research approach is important. Through the abstraction in the process of derivation of the SF, the transfer of research results from one discipline to another is facilitated. In the context of BISE, this could be a particular advantage since here research is integrated into the fields of computer science and business administration.

Finally, the SF methodology also facilitates the transfer of results from fundamental research to more applied research. In the derivation of key principles for business practice from SF it must be noted, however, that the desired generalization here is even counterproductive for a direct application in individual cases as details of the effects investigated in the primary studies may again be relevant. In most cases, SF do not represent a general social "law", but only reasonable assumptions about structural relationships (Houy et al. 2009, p. 32). In business practice, individual recommendations that are derived from SF must be critically examined in the light of the complex relationships in each specific case.

\subsection{Conclusion}

By means of the derivation of SF as summarized and condensed empirical knowledge concerning a given phenomenon, several objectives are achieved. Possibly fragmented knowledge in a field of research is aggregated and structured. Research gaps become obvious. Moreover, the SF may be used as the basis of analytical modeling and the related knowledge 
may be applied to adjacent fields of research in a multi-level research approach. However, SF can only be as good as the underlying empirical research. In that regard, the SF methodology is particularly useful for the stabilization or further development of an existing theory as well as for the transfer of knowledge from basic research to applied research. For the transfer into practice, it is important to note that SF are no general laws, but assumptions that abstract from the individual case. Therefore, it is necessary to refrain from directly using SF as a design statement in individual recommendations without examining the relationships in each specific case.

Barbara E. Weißenberger Chair of Controlling and Business Accounting Justus Liebig University Gießen

\section{Stylized Facts: A contribution to Design-Oriented Business and Information Systems Engineering?}

Stylized facts are generalized descriptions of facts that abstract from empirical descriptions of specific cases in so far that they can be observed in a number of situational contexts and therefore can be widely supported empirically. These facts are artifacts that express empirically tested regularities or patterns statements. They reduce the observational data, ignoring "insignificant" details of those aspects that are considered "interesting" from a "general" scientific perspective and therefore require a convincing explanation.

By talking about a "general" scientific perspective, we mean that the need for explanation is supported by the widest possible community of scientists in the same discipline who may represent different theories and even may belong to various scientific schools or paradigms. Details of situation or context descriptions are considered to be insignificant on the one hand, if these details are not part of a generalized pattern statement. On the other hand, it is proposed to abstract from details that run counter to the generalized pattern of statement as "outliers", but apply only in very specific situational contexts.

The concept of stylized facts can be traced back to contributions by Kaldor to macroeconomic growth theory (Kaldor 1961, pp. 178-179). In the subsequent years it was used in the field of economics in numerous economic contributions (Jones and Romer 2009, pp. 2-3 and 8-25; Li et al. 2010, pp. 71-74, 81 and 89). In business and information systems engineering (BISE), it has hardly been appreciated so far.

To illustrate this issue, the productivity paradox of information technology appears useful (Lin and Shao 2006, pp. 494 495). While it has not yet been discussed as a stylized fact, it offers all the prerequisites to be reconstructed as a stylized fact. Intuitively, one expects that an increased use of information technology in enterprises leads to increased business productivity. Several empirical studies showed, however, that - especially when looking at the level of macroeconomic aggregate measures - either no significant correlation between the use of information technology and business productivity could be proven or that even a negative correlation between these two facts existed. This contradiction to the expectation is seen rightly as a surprise. Since these contradictory findings appeared in a number of situational contexts, it can be - in abstraction from the particular context details - "stylized" to the generalized description of facts that an increased use of information technology in companies is often not associated with increased business productivity.

However, the data are not able to tell whether the increased use of information technology causes the business productivity to be unchanged or even to be reduced - or whether companies of low productivity try to eliminate this deficiency by increasing the use of information technology. Already this simple example shows that the same generalized correlation, which has been found empirically and was generalized via abstraction, can be interpreted in two causally opposite ways without the "pure" data being able to give information as to which of these two competing interpretations is to be preferred. This ambiguity is based on the fact that causality, strictly speaking, never can be observed from empirical data, but represents a concept of imputation. Causality is added interpretively by a subject based on empirical data, but is not taken "objectively" from those data. Therefore, stylized facts should remain free of causal enrichment. Instead, it is recommendable to limit stylized facts to correlations between empirically observed situations and the generalization of these relationships.
Against the background of the research program dispute which has been simmering between German-speaking BISE on the one hand and the Anglo-American Information Systems Research (ISR) on the other hand for several years, it seems appealing to investigate whether the concept of stylized facts can be "taken over" to support either of the above mentioned two adversaries.

As the current mainstream paradigm, ISR dominates the international, mainly Anglo-Saxon journals. Leaning on "scientistic" models from natural science research, ISR prefers large quantitativeempirical analyses for the verification of hypotheses about the behavior of actors when using information and communication systems, and of hypotheses about the impact of this system use. Special emphasis is given to the professional application of sophisticated empirical, especially statistical methods for testing hypotheses. The data, which are checked against the empirical claim to validity of hypotheses, are considered as "given" and are usually not questioned critically. "Hard" data and methods ("rigor") and the belief that reality as it "is" can be described without distortion have become top priorities.

In turn, German-language BISE primarily pursues a constructive and evaluative, i.e. design-oriented research program. Starting from requirements of intended information and communications systems, proposals are developed using "technological" goal-meansstatements on how to design such systems in order to ensure that they meet the requirements as best as possible. The scientific dignity of this research program is not based primarily on the rigidity of the applied research methods, but on the social or economic benefits ("relevance") of the artifacts that it constructs and of the purposes which it is aimed at to fulfill. Just recently, the design-oriented research program was presented in an accentuated way by the key representatives of the field in a Memorandum on design-oriented BISE (Österle et al. 2010, pp. 666-669).

At first glance, the concept of stylized facts appears to correspond to ISR. Both emphasize the importance of empirical facts. This similarity, however, is only superficial. A closer analysis shows that both concepts are contradictory in principle. ISR is based on the assumption of empirical hypotheses that are to be tested. Their origin is generally not questioned. 
They have no direct empirical origin, but are often only taken from vaguely articulated background knowledge. The "hard" empiricism starts only with the data that are used to empirically verify the already available hypotheses.

In contrast, the concept of stylized facts directly ties in with the empirically observed facts. Similar to the concept of "Grounded Theory", the research process starts with empirical observations that are generalized by abstracting from details that are considered to be insignificant. Therefore, the concept of stylized facts is much closer to the empirical basis than the paradigm of hypothesis testing, which predominates in ISR. Moreover, they do not share the naive realism that is so characteristic of ISR. Stylized facts do have an empirical basis, but they "emancipate" from this since they abstract from details which are classified as being insignificant.

For the above mentioned reasons, the concept of stylized facts is not suited to support the mainstream paradigm of ISR. Instead, it seems reasonable to regard stylized facts as a concept in support of the competitive research program of design-oriented BISE. For example, it can be argued that stylized facts represent largely "secured" technological knowledge about empirically observed correlations. If this is correct, then this knowledge could be used to design artifacts of information and communication technology in accordance with the particular requirements.

However, there is one major point adverse to this view. Although stylized facts are generalized descriptions of the relationship between several facts, these descriptions should be - as stated above - limited to empirically observed correlations and should not be "overloaded" with causal interpretations. Therefore, stylized facts are not suitable as technological knowledge for the design of information or communication systems. Instead, design recommendations need knowledge about causal effect relationships that - strictly speaking - cannot be "derived" from the pure generalization of empirical observations, but require additional causal interpretations. Such causal interpretations have nothing in common with the concept of stylized facts in the strict sense.

Nonetheless, the concept of stylized facts can be used as a contribution to support design-oriented BISE in an indirect way. First, in regard to stylized facts it is necessary to identify those explanatory models or theories which are best suited to causally explain the observed and generalized correlations of facts (phenomena). The core of these models or theories is represented by hypothetical statements about the causal relationship between actions and the caused results. Then the models or theories can be used to express both empirically and theoretically wellfounded design recommendations for information and communication technology artifacts.

For the above stated reasons, not the stylized facts themselves but the "underlying" explanatory models or theories prove attractive for design-oriented BISE. Design-oriented BISE requires models or theories with causal explanatory power which are able to give reasons and verify prognoses regarding alleged effects of the recommended design measures. This desideratum of justification becomes evident, for instance, in the above-mentioned memorandum on design-oriented BISE (Österle et al. 2010, pp. 667-668). Although stylized facts are not yet sufficient to provide models or theories with causal explanatory power on their own, they form a "seed of crystallization" for the construction and critical review of such models or theories. Therefore, the concept of stylized facts is a research-programmatic "fruitful" approach to sustainably support designoriented BISE. Particularly promising approaches to operationalize this concept were proposed by Heine et al. (2007, pp. 587-591) as well as by Weißenberger and Löhr (2007, pp. 338-342).

However, considerable skepticism is appropriate as to whether the concept of stylized facts can be implemented successfully in the real-world scientific activities, despite its attractiveness. The main challenge is the normative claim for a scientific community to agree on a "limited" number of phenomena that require a convincing explanation as stylized facts from a "general" scientific perspective. This claim fundamentally conflicts with a liberal and pluralistic scientific community. In this context, also the question of a "power of definition" for the "general" interest for explanation of a scientific community arises. It may not be unrealistic to assume that a "free" discourse cannot be expected in this respect.

Therefore, for the concept of stylized facts to take shape further considerations are required. These must focus on how to achieve a manageable group of stylized facts for the field of BISE with a high potential for approval in the concerned scientific community with regard to the previously mentioned tension between normative standards and academic freedom. An option to implement the concept that is worth considering is that of Delphi studies. These have the advantage of being future-oriented and consensusoriented in principle. A Delphi study tries to find out which issues in a scientific - or also practical - community can achieve an approximate consensus concerning the fact that these issues will play a prominent role in the next decade, for example. Such Delphi studies have already been carried out in the field of BISE, especially by Heinzl et al. (2001, pp. 223-232). As a result of the presumably existing familiarity with this instrument in design-oriented BISE, it would be natural to carry out a Delphi study for the implementation of the concept of stylized facts with the objective of identifying those empirical phenomena which are within the cognitive interest of BISE and which reach a broad consensus on the fact that they still require a convincing explanation.

Such a Delphi study requires a most comprehensive support within the scientific community concerned; hence, it should be actively supported by at least one working group in a relevant professional association. Achieving this support is not a trivial task. In addition, the findings of a Delphi study should not be overestimated. Besides the fact that the result of any empirical study can be doubted with (mostly) good reasons due to its necessary methodological assumptions, no empirical study may usurp normative claims for itself. Similarly, a Delphi study only represents the views of those anonymous scientists who have participated by contributing appropriate information. In view of freedom of research and pluralism - these are values that are insistently supported by the author, even if they are often undermined by research bureaucracy - it does not seem possible to derive any kind of commitment for the members of a scientific community from the small number of respondents in a Delphi study.

Prof. Dr. Stephan Zelewski

Institute of Production and Industrial Information Management University of Duisburg-Essen 


\section{Stylized Facts as a Starting Point of a Theory-Centric Information Systems Engineering Discipline}

Stylized facts are increasingly attracting attention of both management and information systems (IS) engineering (BISE) literature. They enfold complex empirical findings in broad generalizations in order to emphasize empirical regularities or patterns. But like any generalization or abstraction, stylized facts may lack precision. The first examples of stylized facts have been documented in the economic growth theory (Kaldor 1961; Solow 1969). Later, they have been applied and transferred to other application contexts and disciplines (Weißenberger and Löhr 2007; Winter et al. 2009). This is captivating since the author of this statement, who considers himself as an empirical IS researcher, was able to attend Lord Kaldor's inauguration as a honorary doctor of the University of Frankfurt, Germany, during his own graduate studies. Furthermore, he had the opportunity to meet and guide Barbara Weißenberger as a graduate student of the Koblenz School of Corporate Management.

\subsection{How Can Stylized Facts Enrich the IS Discipline?}

Heine et al. (2007) and Houy et al. (2009) suggest a multi-stage approach for deriving stylized facts from a set of data (sources). Based on a "sound" derivation, stylized facts have the potential to make two contributions: (1) They provide evidence for unknown or insufficiently interrogated phenomena that follow causeeffect-relationships and, thereby enrich the context of discovery (Heinrich et al. 2010, p. 78). Thus, they are a starting point for theory development by forming nomological hypotheses about specific phenomena. These hypotheses will be subsequently explained, refined, or refuted. (2) They support existing theories which have the power to explain the stylized facts. In doing so, they serve as an instrument for theory testing. According to the correspondence theory of truth, theoretical statements can be confirmed or refuted by means of observations in the object reality (Heinrich et al. 2010, p. 57).

\subsection{Where Do Data for Stylized Facts Come From?}

Both cases - theory development and theory testing - require a comprehensive set of empirical data as a prerequisite for deriving reproducible stylized facts. During the past decades, other disciplines like economics, for instance, have taken enormous efforts for developing widely accessible data bases. National account systems and public statistics offer a large variety of data items which can be used as a basis for deriving stylized facts. In addition, national science foundations have funded numerous projects which have been developing comprehensive panel data sets for further analysis. In management, panel data sets have been created which contain balance sheet key figures and profit and loss statements from public companies as well as a variety of other financial data. Researchers are offered vast opportunities to develop stylized facts from widely accessible data sources.

What is the situation in IS research, however? Are there any official statistics which contain key data from information systems development and usage, corporate information resources and infrastructures, or information usage itself? Are there private data sources which could be used as an alternative source of data? Unfortunately, the answer is "no". And this is a key issue. How can a researcher derive stylized facts on IT productivity, if corporate software expenses cannot be tracked over a larger panel of companies?

Moreover, secondary data is only rarely available in IS research. Heinrich and Wiesinger (1997) conducted an elaborate literature analysis and found that investigations based on primary data are much more common than investigations based on secondary data. They pointed out that this is caused by the fact that there are virtually no useful sources of secondary data regarding information systems, IT infrastructures, and the use of information in companies. Grün (1997) comes to the conclusion that missing secondary data sources are a serious restriction of empirical research in our discipline. If there were more secondary data, more quantitative-empirical analyses could be conducted.

One could counter argue that companies like Gartner, Forrester, IDC, and the like are in possession of sufficient data to derive stylized facts. But what is the consequence, if these market research organizations are not thoroughly collecting their data in the field but rather extrapolate the data sets with the help of forecasting models like Gompertz curves and only very few data points? And what is the consequence, if none of these organizations is applying standardized measurement models in order to assess the Total-Cost-of-Ownership of Software-asa-Service solutions? The consequences are easy to predict. Methodological issues will create data of low quality which in turn will support the derivation of unreliable stylized facts. Moreover, the market researchers are only offering their data collections for quite a bit of money, which makes the access even more difficult.

Consequently, our discipline requires much time and many resources in order to develop and maintain widely accessible data bases which meet the requirements of a sound derivation of stylized facts. Stimulating progress in this matter is of strategic importance for our discipline and could be rewarding for those readers of this dialogue section who are willing to take up the challenge. One key issue is the question which objects and variables of the IS discipline should be included in such panels. One approach for determining such variables is offered by Heinrich et al. (2010). In the chapter "goals and goal system", important theoretical and practical goals of the BISE discipline are presented. In addition, Houy et al. (2009) have indicated that stylized facts may also be related to structural elements of information systems, like process models. This gives a rough idea of what challenges need to be addressed in order to develop and maintain widely accessible data bases which support the derivation of stylized facts.

\subsection{Implications for Research Strategies in the IS Discipline}

The derivation of stylized facts is part of a theory-driven, quantitative research strategy. It requires a profound theoretical knowledge of IS and neighboring disciplines. It further requires comprehensive methodological know-how of quantitative research methods in the social sciences and economics. According to the experience of the author, who acts as a department editor of a German management and a German IS journal, there is still potential for improvement. Parts of the German-speaking IS community 
are criticizing the increasing influence of theory-driven and empirical research. They act on the (questionable) assumption that empirically grounded theories are not reflecting practical needs. In other words, they are irrelevant and, thus, of little value for IS researchers whose research strategy is the design and development of technological artifacts. Interestingly, this aspect is partially addressed by Houy et al. (2009). They outline that stylized facts, as an instance of a theoretical-empirical research strategy, can inform the praxeologic ${ }^{1}$ design of IT artifacts.

Stylized facts are less generalized than theoretical statements but they must denote regularities which are grounded on empirical data. In particular, researchers must reach a fair consensus regarding particular stylized facts (Houy et al. 2009, p. 25). Reaching such a consensus is on the one hand an empirical fact itself in the sense of the correspondence theory of truth and, on the other hand, denotes a convergent interpretation outcome of the researchers (coherence theory of truth; see Heinrich et al. 2010, p. 58). Thus, stylized facts may be more appealing and relevant for design scientist than abstract theories. They may take the role of boundary objects which offer design scientists the opportunity to participate in the interpretation of relevant and empirically observable findings which are considered to be less abstract.

However, this also creates a peril regarding the application of stylized facts in IS research. Stylized facts could be considered as an oversimplified alternative to rigorous theoretical research which amplifies existing a-theoretical streams in the German-speaking IS community. Instead of untangling hidden but fundamental cause-effect-relationships behind the phenomena observed, design scientists are running the risk to remain in an illustrative and phenomenological, i.e. a non-scientific state of analysis which avoids any serious attempt to include and generalize the existing theoretical knowledge.

\subsection{Epistemological Implications of Stylized Facts}

Every researcher who utilizes stylized facts has to be aware that s/he is encountering all epistemological problems associated with empirism, inductivism, positivism, falsificationism, and realism (Chalmers 2007). But what are the consequences if the world does not obey laws or if individual behavior in IS use is not directly observable? Solow (1969, p. 2) made an interesting point: "There is no doubt that they are stylized, though it is possible to question whether they are facts". Further problems can be expected where cause-effect-relationships are framed as law-like generalizations. As a consequence, one could expect an increasing number of ad-hoc modifications which are inevitable to immunize these law-like generalizations against contradicting observations. Moreover, the range of such theories is likely to be low (Heine et al. 2007). But as long as stylized facts are treated as descriptive and empirically grounded phenomena, they will be less problematic since they represent mere regularities but not laws.

All problems which result from the traditional understanding of the term "theory" as a set of statements can probably be circumvented if other theoretical concepts like structuralism or anti-realistic positions are adopted. The role of stylized facts from the perspective of structuralism is hopefully taken up in the comment from Stephan Zelewski.

Another perspective of interest for design scientists could be the New Experimentalism. It demonstrates, how experimental effects can be achieved through a variety of strategies (like practical intervention, counter tests, error control and error elimination) independent of complex theories (Chalmers 2007, p. 164). A well-known example is the Faraday effect. Michael Faraday interpreted it in 1845 as experimental evidence that light and magnetism are interrelated. However, explaining light through electromagnetic waves has first been theoretically deduced years later by James Clerk Maxwell. The stylized fact of a rotating polarization level of a polarized electromagnetic wave was the decisive hint towards a previously unknown complex theoretic cause-effect-relationship.

\subsection{Conclusion}

Stylized facts represent one way of identifying or refining complex cause-effectrelationships in information systems or information infrastructures if, and only if, the aforementioned problems can be tolerated or solved. But there is one thing that stylized facts cannot do. They are not able to substitute theories or theoretical investigations which explicitly look at these relationships. In contrast, they can help to isolate these relationships and to test them.

If stylized facts are attributed to properties of information systems, like the transparency of process models for instance, they bear the potential to serve as boundary objects for integrating theory and technology. In a worst case scenario, this would at least assure a joint basis for communication between empirical researchers and design scientists in IS research. In a good case scenario it helps to stimulate reciprocal interest between these two types of researchers which is an important prerequisite for informing technology with theory.

For this reason, I would like to express my aspiration in those scholars who are willing to invest their intellectual capital for the development of widely accessible date bases. These data bases are the prerequisite for deriving sound stylized facts. Furthermore, they could stimulate more profound empirical investigations in our field. Supporting these scholars is an important mission of all members in our scientific community.

\section{Prof. Dr. Armin Heinzl \\ Chair of General Management and Information Systems \\ Mannheim University}

\section{An Ambivalent Concept}

To discuss the possible contribution of stylized facts to business and information systems engineering (BISE) research, it is required to clarify the meaning of the concept - which is not trivial regarding its diverse and sometimes superficial use in literature. Stylized facts promise a generalized description of social systems that is empirically grounded, but does not emphasize the claim for general validity like theories. Nevertheless, stylized facts are supposed to be reliable enough to support decision making. Hence, it seems that they may serve as a suitable instrument for BISE research, too. Accounting for the historical context they evolved from allows for developing a more elaborate appreciation of

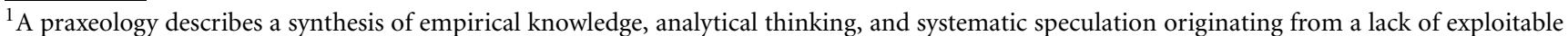
base theories; see Heinrich et al. (2010), p. 89.
} 
stylized facts. When Kaldor suggested the concept in 1968, behaviorist research had already become the leading paradigm in North American economics. While more and more researchers adopted the new paradigm - even though it was not undisputed, its application revealed problems in the actual practice of research that were regarded as dissatisfactory by some. On the one hand, they related to the emphasis on theory testing which requires the existence of adequate theories. Often, however, adequate theories were not available. As a consequence, researchers are tempted to search for knowledge only in the - sometimes diffuse - light of existing theories. On the other hand, the need for statistical procedures may contribute to a selection and preparation of data that blocks the view on interesting aspects. Against this background, Kaldor recommended a "stylized view" when searching for new insights: Empirical observations should be analyzed for general patterns without paying much attention to particular, deviating details. The idealized process to develop stylized facts recommends starting with a comprehensive literature survey to collect results from empirical studies that address a particular research question. Subsequently, similar results are grouped into categories. In the final step, frequent patterns are abstracted to stylized facts. Only rarely, stylized facts have been pursued in Management Science - with different motives. On the one hand, the prevalent focus on theory testing is regarded as inappropriate by some. "In a field that seeks to understand the real world, it makes little sense to always put theory before facts. We must understand at least the broad outlines of 'what' a phenomenon consists of before we try to explain 'why' it occurs" (Helfat 2007, p. 185). However, this is not meant as a racial critique. Instead, the behaviorist approach is not challenged as being the most relevant research method. It is regarded as a prerequisite for developing stylized facts, which in turn serve to inspire behaviorist studies. Hence, they are supposed to act as capacitor and catalyst of empirical research. In contrast to that, authors from "Betriebswirtschaftslehre" regard stylized facts also as an instrument to foster pluralistic use of methods. Sometimes, it is demanded to not only use results from behaviorist research, but to account for other types of empirical research, e.g., hermeneutic approaches, too, in order to enable a richer perspective on the subject through triangulation.

It is not easy to assess stylized facts from a methodological point of view. It seems that Kaldor's proposal was rather motivated by problems he experienced in his actual research practice rather than by methodological considerations. Also, only rarely, authors of subsequent publications on stylized facts aim at methodological assessment (e.g., Heine et al. 2007; Weißenberger and Löhr 2007). On the other hand, it seems that Philosophy of Science has not taken notice of stylized facts so far. A closer look reveals similarities to the "grounded theory" approach which recommends inductively gathering and analyzing data without accounting for existing theories in order to avoid bias. At the same time, the patterns discovered in collected data should be confronted with existing theories later in the process in order to contribute to the further development of theories.

How can the concept of stylized facts be assessed? At first, it does not seem spectacular at all: analyzing a set of facts for common patterns has been a pivotal feature of scientific research. From a methodological perspective it is remarkable that it remains unclear how stylized facts are justified. Superficially, the answer seems obvious: by referring to the analyzed studies. However, that would leave two problems. It is not part of the approach to question the quality of the analyzed studies. Also, stylized facts are an abstraction that needs to be justified as such, too. For a good reason, Heine et al. point at the danger of misuse by opportunistic interpretations (Heine et al. 2007, p. 586), which they illustrate by quoting Solow: " $\mathrm{t}]$ here is no doubt that they are stylized, though it is possible to question whether they are facts."

What are examples of stylized facts in BISE research? Since there seem to be no respective examples in the literature, the following examples were constructed:

- "Due to their risk aversive attitude, IT managers are skeptical towards innovations."

- "IT managers embrace innovations, because they regard them as a chance to strengthen their profile."

- "Modeling improves software quality."

- "Modeling is not positively correlated with software quality."

- "The majority of CIOs in German firms do not have a degree in BISE."

- "The higher the percentage of IT professionals in an organization, the lower are the relative IT costs.”
- "The higher the percentage of IT professionals in an organization, the higher are the relative IT costs."

The examples show that stylized facts can represent interesting patterns - but they do not have to. There is a clear threat that stylized facts might be used to legitimize propositions of little scientific value. This is at least the case as long it is not clarified what makes stylized facts significant from a scientific point of view. Furthermore, the examples illustrate that stylized facts may well be contradictory, if the contingency of the targeted subject was not sufficiently accounted for.

I am hesitant with a concluding judgment. From a methodological point of view I cannot see any original contribution. Nevertheless, stylized facts offer the chance to develop substantial descriptions of the application praxis that go beyond mere anecdotic evidence. However, as long as no sufficient number of empirical studies - which are a prerequisite of developing stylized facts - are available, this chance can hardly be used. With respect to the contingent subject, it should be thoroughly evaluated whether the effort to aim at stylized facts pays off. In this respect, it should also be accounted for the fact that other forms of accessing reality, such as discourses or common projects, may also produce experience that fosters new insights. Also, with respect to the objective to support the construction of future information systems focusing on patterns of factual action is not sufficient. Instead, it requires designing possible worlds, which might be supported by the creation and analysis of - stylized - application scenarios.

Prof. Dr. Ulrich Frank Chair of Information Systems and Enterprise Modelling University of Duisburg-Essen

\section{Idealizations and Stylized Facts}

Winter et al. (2009) introduces the concept of "stylized facts" that describes interdependencies relevant when designing information and communication technology artifacts. He does not provide examples of such facts in the Information Systems (IS) context, but notes that they "abstract from contingent individual cases to an extent that they can be observed in many situations" (p. 197).

The above characterization implies that stylized facts are empirical generalizations. Yet, one can argue that generality in 
science is not achieved by extracting similarities from particulars, but through abstraction and idealization. Indeed, scientific idealizations are common in established disciplines such as physics and economics.

The purpose of the present comment is to argue for scientific idealizations in IS research, suggesting that they may be helpful in identifying useful stylized facts. By Information Systems I refer to the discipline of computing that specifically focuses on IT applications, on their development (including design), use, and impact at individual, group, organizational, community, society and global levels. This application focus makes it possible to distinguish Information Systems from its sister disciplines, Computer Science and Software Engineering, although there is a considerable overlap between the three - raison d'être of each lying in IT artifacts.

Information Systems as a discipline is often criticized that it, with a few exceptions, has failed to produce its own theories in the sense of "theories for explaining and predicting" (Gregor 2006). The major reason for this is that IS research has focused on theories from reference disciplines. Understandably, these theories are void of IT content. Therefore it is no wonder that IT artifacts are weakly addressed in these reference theory-inspired exercises. As an example, quite paradoxically the major theoretical achievement of Information Systems - the original Technology Acceptance Model (TAM) is totally empty of any IT specific substance. The IT substance is just a matter operationalization of perceived ease of use and perceived usefulness.

A second reason for the above failure may be that Information Systems has failed to make scientific idealizations that would be conducive to theory building. These idealizations could help us overcome our commercial culture and address IT artifacts more deeply than has been done so far. Instead of emphasizing technological fashions, discontinuities, radical innovativeness and disruptiveness of every piece of new technology introduced in the marketplace, these idealizations should help us identify technological continuities and invariants.

But what could be these idealizations? Weberian ideal types are instances of scientific idealization in social sciences. They may also useful in understanding IT applications, too. During a few last years I have attempted to develop an open-ended typology of IT applications. In its current form this typology, based on the primary purpose of the IT application, distinguishes eight ideal types: automating, augmenting, mediating, informating, entertaining, artisticizing, accompanying, and fantasizing IT applications. The first four correspond to quite traditional IT applications that automate some processes, serve as productivity tools, provide computer mediated communication, and serve as information systems in proper. Computer games are examples of IT applications with the primary purpose to entertain. IT applications may also attempt to arouse artistic experience, and one can easily imagine a new sort of art that is essentially built on the dynamic and interactive character of computer technology. IT artifacts such as digital pets can accompany human users. Finally, computers allow users to co-construct and co-experience digital fantasy worlds.

The underlying conjecture is that each ideal type has its characteristic - although not exclusive - designable qualities. For example, technical quality in the case of automating applications, usability of augmenting applications, useruser-interactivity of mediating applications, information quality in the case of informating applications, engageability of entertaining applications, aesthetics of artisticizing applications, emotional quality of accompanying applications, and identity constructability in the case of fantasizing applications.

The typology of IT applications broadens the focus of Information Systems beyond the utilitarian use of IT applications in the workplace context. That is another story, but there are clear signs that this broadening is slowly taking place.

As ideal types, the eight types do not necessarily occur in reality in their pure forms, but most real applications are combinations of them. In fact, based on the eight types alone, we can identify 255 different combinations. If one adds different application domains (e.g., business, government, healthcare, education, etc), one could have thousands of different application types just in terms of the eight ideal types.

My guess is that the major evolution and perhaps advances in IT will take place at the level of IT applications. It is obvious that we should have some intellectual means to address the increased variety of IT applications. Instead of focusing on all thousand IT application types or the 255 combinations separately, research could focus on the eight (or so) ideal types, assuming that deeper understanding of their design and use also informs about the hybrid applications.

So, when talking about stylized facts, I have in mind empirically grounded interdependencies such as perceived ease of use ( $\approx$ usability) is positively associated with perceived usefulness and perceived usefulness is positively associated with behavioral intention to use as originally identified in TAM research in the context of augmenting tools (Davis et al. 1989). Yet, I wish that we could have stylized facts that are much richer in technology and in identifying significant designable qualities of various IT applications. Our search for stylized facts could focus on how to successfully design successful IT applications that automate, augment, mediate, informate, entertain, artisticize, accompany, and help us fantasize. That is my vision.

Juhani Iivari
Department of Information Processing
Science
Oulu University, Finland

\section{References}

to Sect. 1:

Fettke P, Houy C, Loos P (2010) On the importance of design knowledge for designoriented business and information systems engineering - conceptual foundations, application example, and implications. Business \& Information Systems Engineering 2(6):347-358

Houy C, Fettke P, Loos P (2009) Stilisierte Fakten der Ereignisgesteuerten Prozesskette - Anwendung einer Methode zur Theoriebildung in der Wirtschaftsinformatik. In: Nüttgens $M$, Rump FJ, Mendling J, Gehrke N (eds) EPK 2009. GI-Workshop - "Geschäftsprozessmanagement mit Ereignisgesteuerten Prozessketten" (WI-EPK$09)$, November 26-27. Gesellschaft für Informatik, Berlin, pp 22-41

Houy C, Fettke P, Loos P (2011) Stilisierte Fakten in der gestaltungsorientierten Wirtschaftsinformatik - Allgemeine Potentiale und erste Erfahrungen. In: Tagungsband zur Konferenz Wirtschaftsinformatik 2011. Internationale Tagung Wirtschaftsinformatik (WI-11), February 16-18, Zürich

Winter R, Krcmar H, Sinz EJ, Zelewski S, Hevner AR (2009) What in fact is fundamental research in business and information systems engineering? Business \& Information Systems Engineering 1(2):192-198

\section{to Sect. 2:}

Becker W, Benz K (1997) Effizienz-Verständnis und Effizienz-Instrumente des Controlling. DBW 57:655-671 
Denzin N, Lincoln Y (2000) The discipline and practice of qualitative research. In: Denzin $\mathrm{N}$, Lincoln $\mathrm{Y}$ (eds) Handbook of qualitative research. Sage, Thousand Oaks

Forster M, Benlian A, Hess T (2009) Investitionsentscheidung pro oder contra ERPSysteme. In: Hess T (ed) Controlling mit ERP-Systemen, ZfCM - Sonderheft 3/2009

Heidmann M (2008) The role of management accounting systems in strategic sensemaking. Gabler, Wiesbaden

Heine BO, Meyer M, Strangfeld O (2007) Das Konzept der stilisierten Fakten zur Messung und Bewertung wissenschaftlichen Fortschritts. Die Betriebswirtschaft 67(5):583-601

Hitt M, Beamish P, Jackson S, Mathieu J (2007) Building theoretical and empirical bridges across levels: multilevel research in management. AMJ 50:1385-1399

Houy C, Fettke P, Loos P (2009) Stilisierte Fakten der Ereignisgesteuerten Prozesskette Anwendung einer Methode zur Theoriebildung in der Wirtschaftsinformatik. In: Nüttgens M, Rump FJ, Mendling J, Gehrke N (eds) EPK 2009. GI-Workshop - AK "Geschäftsprozessmanagement mit Ereignisgesteuerten Prozessketten“ (WI-EPK-EPK), November 26-27. Gesellschaft für Informatik, Berlin, pp 22-41

loannidis JPA (2005) Why most published research findings are false: In: PLoS Medicine 2:124e

Kaldor N (1961) Capital accumulation and economic growth. In: Lutz F, Hague D (eds) The theory of capital. Macmillan, London

Löhr B (2010) Integriertes Risikocontrolling für Industrieunternehmen. Peter Lang, Frankfurt

Rosenhagen K (1994) Informationsversorgung von Führungskräften. Controlling 6:272-280

Schreyögg G (2007) Betriebswirtschaftslehre nur noch als Etikett. In: Gerum E, Schreyögg $\mathrm{G}$ (eds) Zukunft der Betriebswirtschaftslehre, zfbf - Sonderheft, vol 56

Schwerin J (2001) Wachstumsdynamik in Transformationsökonomien. Böhlau, Köln

Weißenberger BE, Löhr B (2007) Planung und Unternehmenserfolg: Stylized Facts aus der empirischen Controllingforschung im deutschsprachigen Raum von 19902007. ZP 18:335-363

Winter R, Krcmar H, Sinz EJ, Zelewski S, Hevner AR (2009) Was ist eigentlich Grundlagenforschung in der Wirtschaftsinformatik? WIRTSCHAFTSINFORMATIK 51(2):224-231

\section{to Sect. 3:}

Heine BO, Meyer M, Strangfeld O (2007) Das Konzept der stilisierten Fakten zur Mes- sung und Bewertung wissenschaftlichen Fortschritts. Die Betriebswirtschaft 67(5):583-601

Jones Cl, Romer PM (2009) The new Kaldor facts: ideas, institutions, population, and human capital. Paper, Version 2:0 vom 2009-06-17. Stanford

Heinzl A, König W, Hack J (2001) Erkenntnisziele der Wirtschaftsinformatik in den nächsten drei und zehn Jahren. WIRTSCHAFTSINFORMATIK 43(3):223-233

Kaldor N (1961) Capital accumulation and economic growth. In: Lutz FA, Hague DC (eds) The theory of capital. MacMillan, London, pp 177-222

Li Y, Hamill PA, Opong KK (2010) Do benchmark African equity indices exhibit the stylized facts? Global Finance Journal 21(1):7197

Lin WT, Shao BBM (2006) The business value of information technology and inputs substitution: the productivity paradox revisited. Decision Support Systems 42(2):493507

Österle $\mathrm{H}$, Becker J, Frank U, Hess T, Karagiannis $D$, Krcmar $H$, Loos $P$, Mertens $P$, Oberweis A, Sinz EJ (2010) Memorandum zur gestaltungsorientierten Wirtschaftsinformatik. Schmalenbachs Zeitschrift für betriebswirtschaftliche Forschung 62(9):662672

Weißenberger BE, Löhr B (2007) Planung und Unternehmenserfolg: Stylized Facts aus der empirischen Controllingforschung im deutschsprachigen Raum von 19902007. Zeitschrift für Planung und Unternehmenssteuerung 18(4):335-363

\section{to Sect. 4:}

Chalmers AF (2007) Wege der Wissenschaft - Einführung in die Wissenschaftstheorie, 6 edn. Springer, Berlin

Grün O (1997) Zum Stand der empirischen Forschung in der Wirtschaftsinformatik aus betriebswirtschaftlicher Sicht. In: Grün $\mathrm{O}$ Heinrich LJ (eds) Wirtschaftsinformatik: Ergebnisse empirischer Forschung. Springer Wien, pp 51-60

Heine BO, Meyer M, Strangfeld O (2007) Das Konzept der stilisierten Fakten zur Messung und Bewertung wissenschaftlichen Fortschritts. Die Betriebswirtschaft 67(5):583-601

Heinrich LJ, Heinzl A, Riedl R (2010) Wirtschaftsinformatik: Einführung und Grundlegung, 4 edn. Springer, Heidelberg

Heinrich LJ, Wiesinger I (1997) Zur Verbreitung empirischer Forschung in der Wirtschaftsinformatik. In: Grün $\mathrm{O}$, Heinrich LJ (eds) Wirtschaftsinformatik: Ergebnisse empirischer Forschung. Springer, Wien, pp 37-49

Houy C, Fettke P, Loos P (2009) Stilisierte Fakten der Ereignisgesteuerten Prozesskette - Anwendung einer Methode zur Theoriebildung in der Wirtschaftsinformatik. In: Nüttgens $M$, Rump FJ, Mendling J, Gehrke N (eds) EPK 2009: Gl-Workshop - „Geschäftsprozessmanagement mit Ereignisgesteuerten Prozessketten" (WI-EPK09), November 26-27, Berlin, pp 22-41

Kaldor N (1961) Capital accumulation and economic growth. In: Hague DC, Lutz FA (eds) The theory of capital. MacMillan, London, pp 177-222

Solow RM (1969) Growth theory: an exposition. Clarendon, New York

Weißenberger BE, Löhr B (2007) Planung und Unternehmenserfolg: Stylized Facts aus der empirischen Controllingforschung im deutschsprachigen Raum von 19902007. Zeitschrift für Planung \& Unternehmenssteuerung 18(4):335-363

Winter R, Krcmar H, Sinz EJ, Zelewski S, Hevner AR (2009) Was ist eigentlich Grundlagenforschung in der Wirtschaftsinformatik? WIRTSCHAFTSINFORMATIK 51(2):224231

\section{to Sect. 5:}

Heine BO, Meyer M, Strangfeld O (2007) Das Konzept der stilisierten Fakten zur Messung und Bewertung wissenschaftlichen Fortschritts. Die Betriebswirtschaft 67(5):583-601

Helfat CE (2007) Stylized facts, empirical research and theory development in management. Strategic Organization 5(2):185192

Weißenberger BE, Löhr B (2007) Planung und Unternehmenserfolg: Stylized Facts aus der empirischen Controllingforschung im deutschsprachigen Raum von 19902007. Zeitschrift für Planung \& Unternehmenssteuerung 18(4):335-363

\section{to Sect. 6:}

Davis FD, Bagozzi RP, Warshaw PR (1989) User acceptance of computer technology: a comparison of two theoretical models. Management Science 35(8):982-1003

Gregor S (2006) The nature of theory in information systems. MIS Quarterly 30(3):611642

Winter R, Krcmar H, Sinz EJ, Zelewski S, Hevner AR (2009) What in fact is fundamental research in business and information systems engineering? Business \& Information Systems Engineering 1(2):192-198 


\section{0 0010000001010100 0111001001100001 0110100101101110 0110010101100101}

Sie sehen hier mehr als Nullen und Einsen?

Wir sehen Ihre Karriere im Traineeprogramm IT. Als spätere Fach- oder Führungskraft.

www.perspektiven.allianz.de

\section{Allianz (11)}




\section{COMMERZBANK}

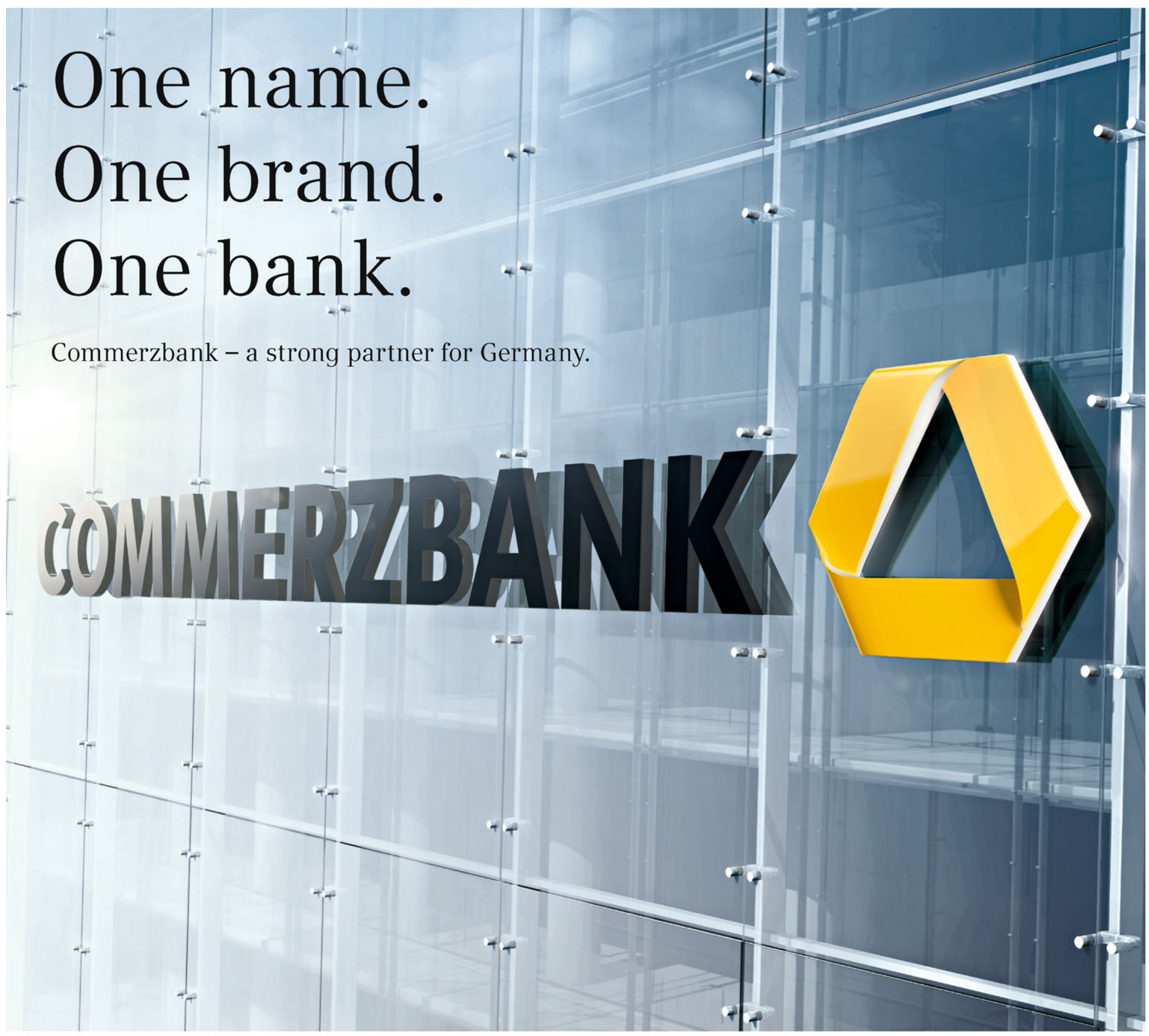

The new Commerzbank unites the strengths of Commerzbank and Dresdner Bank. As the leading bank for retail and corporate clients in Germany, we combine strong local links and a long tradition with the end-to-end expertise and power of an international network. In this way, we live our core values of partnership and performance: in our dealings with clients, investors and employees, and in providing outstanding quality and service. This makes us a reliable, strong long-term partnerGermany's bank of choice. www.commerzbank.com 


\section{Business oder Technologie?}

Wieso oder?

\section{Oder kennen Sie ein Business,}

das ohne Technologie auskommt?

McKinsey sucht Berater(innen) für das Business Technology Office.

Der effektive Einsatz von Technologie löst unternehmerische Probleme und steigert somit den substanziellen Wert eines Unternehmens nachhaltig. Genau das ist das Ziel unserer Beratung. Wir helfen unseren Klienten, Investitionen in Technologie erfolgreich zu managen und mit den strategischen Prioritäten des Geschäfts in Einklang zu bringen. Wenn Sie diese vielfältige Herausforderung annehmen, werden Sie auf über 500 Kollegen an rund 50 Standorten in mehr als 25 Ländern treffen.

Und werden damit Teil des globalen Business Technology Office - eines der größten und am schnellsten wachsenden Büros von McKinsey \& Company. Alle weiteren Informationen finden Sie auf unserem Karriereportal.

bto.mckinsey.de 

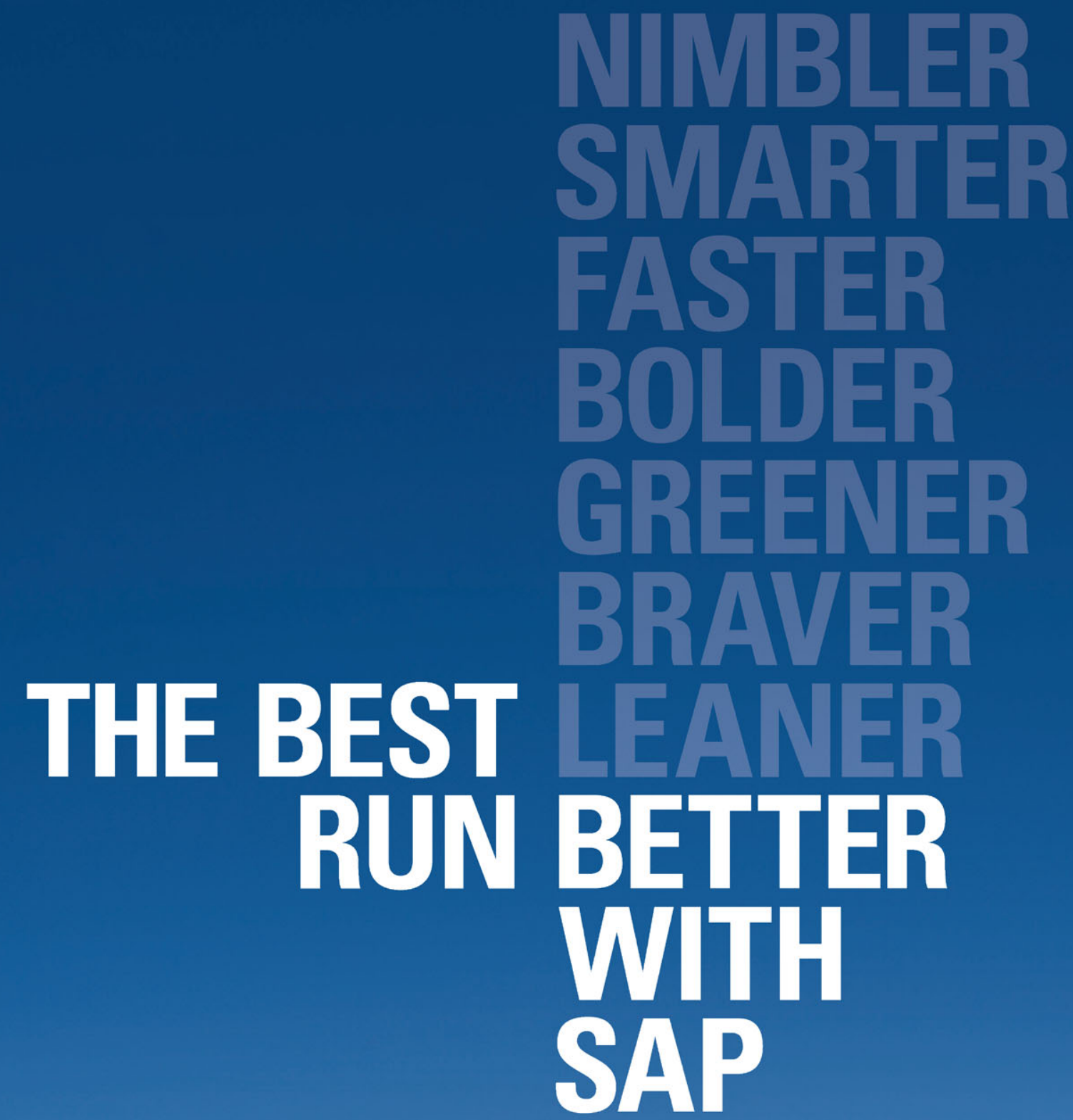

SAP HELPS THE WORLD'S GREATEST COMPANIES DO WHAT THEY DO BEST, EVEN BETTER.

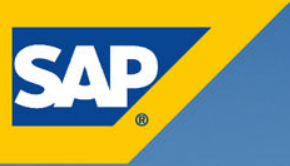

Whether helping companies out-compete, out-innovate, out-serve or out-transform their competitors, SAP has but one goal - to make every business a best-run business.

Our software is designed for it. Our company revolves around it. Our people are obsessed with it.

Find out what SAP can do for your business at sap.com/better

.




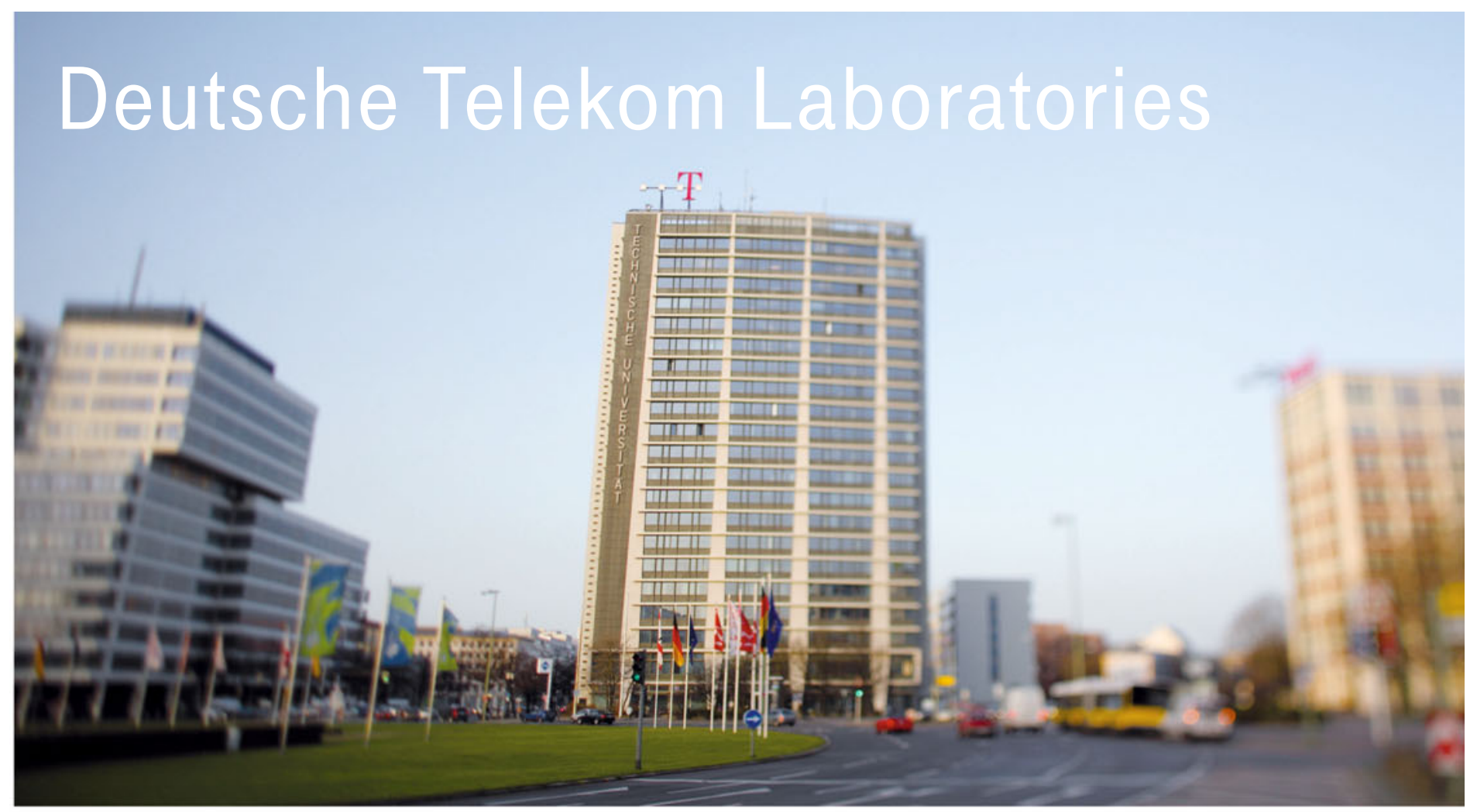

\section{We shape the future}

Deutsche Telekom Laboratories are Telekom's research and development institute. Established under private law, this scientific facility is an affiliated institute of the renowned Technische Universität (TU) Berlin. At Telekom Laboratories, some 360 scientists from around the world and experts from the Telekom Group develop new, innovative services and solutions for the Group's customers. The founding of start-up companies is another way the Group utilizes Telekom Laboratories' results.

Cooperation with the TU Berlin, other universities and industry partners creates a bridge between business and science in order to turn ideas into marketable innovations as quickly as possible. Telekom Laboratories' innovative processes are based on "open innovation" principles that enable the free exchange of ideas and information between selected institutions and companies. The objective is to capture synergy effects and to continue enhancing research results, as quickly and efficiently as possible, through interchange. This also encompasses the inclusion of users and customers in the innovation process, as enabled by a number of inventive methods.

As part of its activities, Telekom Laboratories focuses on four domains:

- Products \& Applications

- Infrastructure

- Security

- User-centered Innovation

The business and information systems engineering offers useful interdisciplinary approaches for all these areas of innovation. Subject matter includes, for example, modeling, methods and tools for process innovations, agile architectures for information and communication technologies (ICT), technology-oriented management approaches and techno-economic assessments. The aim is to safeguard the economic sustainability of innovations for the Group.
Telekom Laboratories is divided into two areas: The Innovation Development Laboratory focuses on near-market developments with a time horizon of 18 months to three years. In the Strategic Research Laboratory, scientists holding seven professorships work on long-term technology and applied research.

Aside from its Berlin headquarters, Telekom Laboratories also operate facilities in Darmstadt (Germany), Beer Sheva (Israel) and Los Altos (United States).

Contact:

Deutsche Telekom Laboratories Ernst-Reuter-Platz 7, 10587 Berlin E-mail:wi.laboratories@telekom.de www.laboratories.telekom.com

\section{Deutsche Telekom Laboratories}




\section{We proudly present}

BUSINESS \& INFORMATION SYSTEMS ENGINEERING
QSpringerLink

Wunbise-journal.org
Business \& Information Systems Engineering (BISE) is the new peer-reviewed scholarly e-journal for the entire techno-economically oriented community with a focus on design science-oriented research. It continues the 50 years' tradition of the journal WIRTSCHAFTSINFORMATIK by that all articles appear both in English and in German. Moreover, authors benefit from our double-blind, constructive, and rapid review process.

"I believe the time is opportune for the IS community to provide such outlets for design researchers. BISE, however, has some unique advantages for positioning itself as a desirable outlet for design science research." 


\section{How to generate value in times of tight resources}

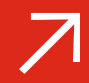

WWW.GABLER.DE

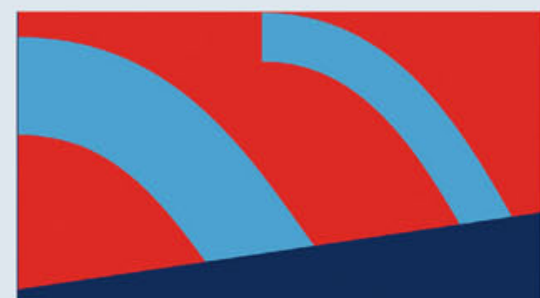

D. Buchta / M. Eul

H. Schulte-Croonenberg

Strategic IT Management

Increase value, control performance,

reduce costs

3rd edition

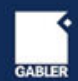

Dirk Buchta / Marcus Eul / Helmut Schulte-Croonenberg

\section{Strategic IT-Management}

Increase value, control performance, reduce costs

3. Aufl. 2010. 224 pp. Hardc. EUR 49,95

ISBN 978-3-8349-1825-3

IT is not a cost factor but a tool in order to cut process costs in a company. This message cannot be elaborated enough in times of restrictive budgets. The book focuses on how a company with tight resources can generate value - using standard as well as individual software. New: With a focus on Green IT-Green Business.

\section{Content}

- Part A: Enhancing Value-IT as a Value Driver for the Company

1. IT Strategy

2. Enterprise Transformation

3. IT Merger Integration and IT Carve-Out

4. Green IT and Green Business

- Part B: Controlling Performance-Value-oriented IT Management

1. IT Governance

2. IT Planning

3. IT Performance Management

- Part C: Reducing Costs-Increasing Efficiency and Effectiveness through IT

1. IT Optimization

2. In-House IT Service Providers

3. IT Outsourcing and IT Offshoring

\section{The Authors}

Dr.-Ing. Dirk Buchta is Vice President and Partner of A.T. Kearney.

Dr. Marcus Eul is Vice President and Partner of A.T. Kearney.

Dr. Helmut Schulte-Croonenberg is Vice President and Partner of A.T. Kearney. 


\section{Strategic International Management in 20 lessons on key issues}

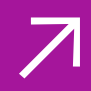

WWW.GABLER.DE

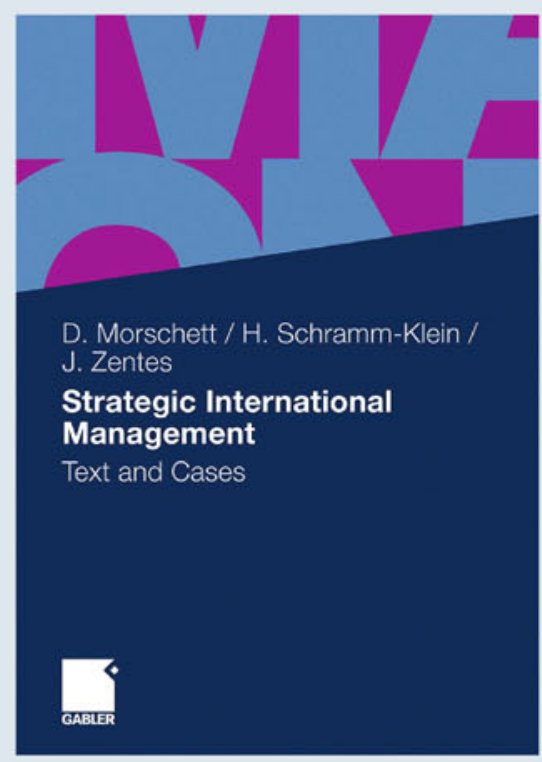

Dirk Morschett / Hanna Schramm-Klein / Joachim Zentes

Strategic International Management

Text and Cases

2. Ed. 2010. X, 470 pp. Softc. EUR 42,00

ISBN 978-3-8349-2535-0

„Strategic International Management" takes a global perspective and covers the major aspects of international business strategies, the coordination of international companies and the particularities of international value chain activities and management functions. The book provides a thorough understanding of how Production \& Sourcing, Research \& Development, Marketing, Human Resource Management and Controlling have to be designed in an international company and what models are available to understand those activities in an international context.

The book offers 20 lessons that provide a comprehensive overview of all key issues. Each lesson is accompanied by a case study from an international company to facilitate the understanding of all important factors involved in strategic international management.

In this second edition, all chapters have been updated, all case studies revised and recent data were integrated. The concept, though, remained unchanged.

\section{Content}

- Introduction to Strategic International Management

- The External Environment

- International Coordination

- Foreign Operation Modes

- Selected Value Chain Activities

- Selected International Business Functions

\section{The Authors}

Dirk Morschett is Professor of International Management at the University of Fribourg, Switzerland. He holds the Liebherr/Richemont Endowed Chair for International Management and is responsible for the Master of Arts in European Business at the University of Fribourg. Hanna Schramm-Klein is Professor of Marketing at the University of Siegen, Germany. She holds a Chair for Marketing and teaches International Marketing, Marketing and International Management at the University of Siegen and in different MBA programmes.

Joachim Zentes is Professor of Management and Marketing at the Saarland University, Saarbrücken, Germany. He is Director of the H.I.MA. (Institute for Commerce \& International Marketing) and Director of the Europa-Institut at Saarland University. He holds a Chair in Business Adminstration, with a focus on Foreign Trade and International Management. 